ness of the husk are related to the percentage of oil. Two interesting papers were contributed by Prof. Hendrick, one showing the composition of water draining from soils practically free from carbonate of lime, and the other emphasising the value as manure of waste carbonate of lime.

A new line of agricultural study was opened up by Dr. W. G. Smith and Mr. Crampton, in a paper on the influence of origin and topography on grass lands. This is one of the earliest applications of the new ecological knowledge to agriculture.

$\mathrm{Mr}$. Collins contributed a paper on the evolution of hydrocyanic acid from linseed, and several papers of economic interest were read by other members.

\section{THE PALETTE OF THE ILLUMINATOR FROM THE SEVENTH TO THE END OF THE FIFTEENTH CENTURY. ${ }^{1}$}

$\mathrm{I}$ the opening lecture given at the Royal Academy of Arts last year, Dr. Laurie dealt with the question of the history of the pigments used at varjous times by painters, bringing together such information as could be obtained by a literary inquiry. Since then he has made an examination with the microscope of a large number of illuminated manuscripts at the British Museum, the Advocates' Library, Edinburgh, and the Edinburgh University Library, from the seventh to the end of the fifteenth century. The result of this examination has made it possible to identify the larger number of pigments used, and classify them according to the centuries and according to different countries, Byzantine, Irish, French, English, Italian, and German manuscripts having been examined.

The general results are to show that during these centuries the palette was practically confined to vermilion, whether natural or artificial, red lead, orpiment, ultramarine and ultramarine ash, azurite, malachite, natural and artificial, verdigris, lakes, and preparations of the nature of Tyrian purple, with the addition of a remarkable transparent green used from the eighth to the fourteenth century, which owes its pigmentary value to copper, although it has not been possible to determine exactly the nature of the compound. A green closely resembling it in appearance and properties can, however, be prepared by dissolving verdigris in Canada balsam or other semi-liquid pine resins. In no case were any specimens of the Egyptian blue which was used so largely in classical times found on the manuscripts. It therefore seems probable that the method of manufacture of this conner silicate was lost before the seventh century.

In addition to these pigments, earth colours were occasionally used, and there are rarely present some pigments which it is difficult to classify. The lake used after the thirteenth century is closely matched by lac lake, which was introduced for dyeing purposes about that time, and on the manuscripts of the late fifteenth century a fine lake appears, which in one case has been identified with every probability as madder lake. The tests, however, cannot be regarded as absolutely conclusive.

No fresh light beyond that contained in the known records can be thrown on the mediums used, with the exception that on one later fifteenth-century manuscript the medium has been proved to be beeswax.

All the pigments mentioned on the above list were not used in the same countries at the same time. It is possible to show a gradual improvement, for instance, in the preparation of ultramarine from lapis lazuli. The use of a fine verdigris is not found until

I Abstract of the opening lecture delivered at the Royal Academy of Arts on December 2 by Dr. A. P. Iaarie.

No. 2249, vol. 90] the beginning of the fifteenth century, and azurites of different quality appear and disappear at definite dates, while a marked distinction can be drawn between the palette used in Byzantium and Ireland, and that used in the rest of Europe from the tenth century. There are also remarkable examples of the use of gold dust, while the laying of golf leaf on raised gesso does not appear earlier than the eleventh century, and only becomes common in the twelfth century.

The whole result of the investigation is to settle with considerable exactness the actual pigments in use, and it is probable that the results will be of value in assisting in fixing the dates of doubtful manuscripts.

It will be noted that the pigments are almost entirely mineral in character. They are in all cases coarsely ground, and the decorative effect is largely due to the coarse crystalline particles resulting in a broken surface.

The detailed results of the investigation were laid before the Society of Antiquaries on November 28, and are being published by that society.

\section{UNIVERSITY AND EDUCATIONAL INTELLIGENCE.}

OxFORD.-On November 28 the preamble of a statute supplementing the ordinary form of procedure in Convocation by providing in certain circumstances for a special poll was moved by Prof. Geldart, supported by the Master of Balliol, and opposed on various grounds by Prof. Oman, Prof. Myres, and the president of Corpus. A division in a thin house showed twenty-five in favour of the preamble and twenty-four against it.

Sir William Mitchell Ramsay has been appointed Romanes lecturer for I9I3. His subject has not yet been announced.

THE prizes and certificates gained by students of the Sir John Cass Technical Institute during the past session will be distributed by Prof. Selwyn Image, Slade professor of fine art, Oxford University, on Tuesday, December ro, at 8 p.m.

$I_{N}$ reply to a question asked in the House of Commons on Monday, Mr. Wedgwood Benn said:- "The Government is under no promise to find a new site for the London University, and it is not intended to use part of the Botanic Gardens for this purpose."

In the House of Commons on Tuesday, the Prime Minister was asked whether he was aware that in Igog the Chancellor of Oxford University issued a inemorandum urging the reform of Convocation and greater facilities for students of limited means, and that neither of these reforms had been attempted; and whether the Government was now prepared to advise that a Royal Commission be appointed to carry through those reforms. In reply, Mr. Asquith said :"I am well aware of the importance of these matters and have given them much attention. I hope shortly to be able to make a definite statement on the subject."

The Marquess of Northampton, K.G., will distribute the prizes and certificates at the Northampton Polytechnic Institute, Clerkenwell, to-morrow, December 6. The laboratories, workshops, \&c., with various exhibits in them, will be open for inspection on that occasion, and also on Saturday evening. There will be kinematograph illustrations of twisting and breaking, by Mr. C. E. Larard; demonstrations with liquid air, by Mr. W. M. Wilcox; and an illustrated lecturette on notable bookbindings, by Mr. T. E. Harrison. 